\title{
Hipomagnesemia e hipocalcemia en relación con el uso de cetuximab
}

Cetuximab es un anticuerpo monoclonal contra el receptor del factor de crecimiento epidérmico perteneciente a la familia de receptores tirosinkinasa HER. El receptor bloqueado por Cetuximab es concretamente el HER 1, c-erb1 o EGFR (en adelante nos referiremos al receptor con este último término). Cetuximab tiene una afinidad por EGFR 10 veces superior a su ligando natural.

El fármaco se ha incorporado en los últimos años al tratamiento de una serie de tumores, principalmente el cáncer colorrectal metastático y los tumores del área ORL, tanto en combinación con quimioterapia como con radioterapia ${ }^{1,2}$.

El cetuximab, al igual que otros anticuerpos monoclonales, presenta un perfil de toxicidad totalmente distinto y "más benevolente" que los agentes quimioterápicos clásicos. De sus efectos secundarios, el más conocido es la toxicidad cutánea en forma de rash acneiforme.

Sin embargo, y dada su reciente incorporación al arsenal terapéutico en oncología, algunos efectos tóxicos poco conocidos pueden ir apareciendo con la extensión de su uso.

Presentamos el caso de un paciente varón en tratamiento con irinotecan, 5 FU, Leucovorin y cetuximab por un carcinoma colorrectal metastático que acudió al servicio de urgencias por un cuadro de fatiga severa, parestesias en manos y pies, debilidad de aparición rápidamente progresiva y diarrea grado I. Entre los datos analíticos realizados en urgencias destacaba la ausencia de anemia que justificara la astenia; sin embargo se detectó la presencia de hipocalcemia, por lo que el cuadro fue inicialmente atribuido al descenso sérico de la calcemia (corregida: $7,7 \mathrm{mg} / \mathrm{dl}$ ). El paciente no recibía tratamiento con otras medicaciones capaces de provocar hipocalcemia (tiazidas, cisplatino, aminoglucósidos,...). Se procedió a instaurar tratamiento con reposición de hidroelectrolitos, haciendo especial hincapié en el calcio mediante la infusión de gluconato cálcico hasta recuperar una calcemia en niveles normales. Sin embargo, la clínica del paciente no se recuperó de la misma manera, al tiempo que la cifra de calcemia volvía a disminuir por debajo incluso de sus cifras iniciales $\left(6.0 \mathrm{mg} / \mathrm{dl}\right.$ el $2^{\circ}$ día de estancia en el hospital) a pesar de una reposición más que generosa. Por dicho motivo, se procedió al ingreso del paciente y se solicitó, entre otra posibles causas de la clínica, una determinación de magnesemia, que arrojó un resultado de $0.8 \mathrm{mg} / \mathrm{dl}$, compatible con una hipomagnesemia grado $\mathrm{III}^{3}$ (Ver Tabla I). Durante ese día y el siguiente, se añadió al tratamiento del paciente suplementos de magnesio vía i.v., con lo que se consiguió la progresiva normalización de la cifra de magnesio y de calcio séricos, así como la desaparición de la sintomatología del paciente. Tras el alta el paciente continuó recibiendo aporte oral de magnesio y se extremó la monitorización electrolítica de todos los pacientes que están recibiendo cetuximab.

TABLA I

\begin{tabular}{|lcccccc|}
\hline Analítica & Día $1^{o}$ & Día $1^{\circ}$ & Día $2^{o}$ & Día $2^{o}$ & Día $2^{o}$ & Día $3^{\circ}$ \\
\hline Calcio (mg/dl) & 7.7 & 5.5 & 6 & 6.5 & 7.3 & 7 \\
Magnesio (mg/dl) & - & 0.8 & 0.9 & 1.2 & 1.3 & 1.5 \\
\hline
\end{tabular}

A raíz de este caso llevamos a cabo una revisión de las cifras electrolíticas de los pacientes que habían recibido tratamiento con cetuximab desde el inicio de su uso en nuestro servicio. Encontramos dos casos más de hipocalcemia, con cifras corregidas de calcio sérico de forma repetida de hasta 6.2 $\mathrm{mg} / \mathrm{dl}$. Desgraciadamente, y en parte debido a la au- 
sencia de sintomatología en estos dos últimos casos (ambas pacientes mujeres en tratamiento de cáncer colorrectal metastásico con irinotecan, $5 \mathrm{FU}$, Leucovarin y cetuximab) y a la ausencia de nuevos episodios en ellas, no se solicitaron las cifras de magnesemia.

Varios son los factores que pueden dificultar el diagnóstico de hipomagnesemia en pacientes con una clínica similar: por una parte, la astenia es una manifestación muy frecuente entre los pacientes oncológicos y cuya etiología es multifactorial; por otra, muchos pacientes con cáncer colorrectal han recibido previamente tratamiento con oxaliplatino, causante con mucha frecuencia de parestesias que los enfermos presentan hasta mucho tiempo después de haber finalizado el tratamiento. Además, establecer la relación causal no es sencillo en pacientes que suelen tomar otras medicaciones, varias de ellas capaces de causar depleción de electrolitos, entre ellos el magnesio (diuréticos y otros antihipertensivos, antibióticos, ácido zoledrónico,...)

Ante este caso de hipomagnesemia en probable relación con el uso de cetuximab, realizamos una búsqueda bibliográfica que mostró un único caso comunicado en la literatura médica hasta el momento (junio 2006) . $^{4}$

Por otra parte, entre los posibles mecanismos implicados, se sugiere un bloqueo del transporte activo de magnesio en el asa de Henle y en el túbulo contorneado distal (TCD), lugares donde también se encuentra sobreexpresado el EGFR. Se postula con un posible bloqueo de la proteína TRPM6, miembro de una familia de receptores de canales catiónicos, implicada en el transporte activo de magnesio en la nefrona ${ }^{5,6}$.

El bloqueo de EGFR en el asa de Henle y TCD podría afectar de forma reversible la función de TRPM6 en el transporte de magnesio extracelular, que sería eliminado en exceso a través de la orina. En nuestro caso no disponemos de evidencia directa de esto pues no solicitamos la medición de la cifra de magnesuria.

Otro posible mecanismo implicado podría ser la inhibición de la TRPM6 en las microvellosidades del intestino delgado, lugar también de sobreexpresión de EGFR, lo que provocaría una disminución de la absorción intestinal de magnesio. Sin embargo, de este mecanismo existen menos evidencias.

En definitiva, y aunque los ensayos clínicos reali- zados hasta la aprobación de cetuximab y las posteriores guías clínicas no hacen especial mención de ello, consideramos de interés la monitorización de las cifras electrolíticas, en especial de calcio y magnesio, en los pacientes que estén recibiendo cetuximab. Queremos destacar también el hecho de que en pacientes en tratamiento con cetuximab una hipocalcemia puede estar causada primariamente por un descenso de la cifra de magnesio sérico y que hasta que no se corrija la misma, no se logrará la normalización de las cifras de calcemia ni el control de la clínica del paciente.

\section{Marrupe, M. Méndez, R. Quibén, P. López, J. Churruca ${ }^{1}$ Oncología Médica. ${ }^{1}$ Medicina Interna. Hospital General de Móstoles (Madrid)}

\section{Bibliografía}

1. Cunningham D, Humblet Y, Siena S, Khayat D, Bleiberg H, Santoro A, et al. Cetuximab monotherapy and cetuximab plus irinotecan in irinotecan-refractory metastatic colorectal cancer. N Engl J Med 2004: 351; 337-345.

2. Bonner JA, Harari PM, Giralt J, Azarnia N, Shin DM, Cohen $\mathrm{RB}$ et al. Radiotherapy plus cetuximab for squamous cell carcinoma of head and neck. N Engl J Med. 2006 Feb 9;354(6):567-78

3. National Cancer Institute Common Toxicity and Adverse Event Criteria for Serum Calcium and Magnesium. http://ctep.cancer.gov/forms/CTCAEV3.pdf

4. Schrag D, Ki Young Choung, Flombaum C, Saltz L. Cetuximab therapy and symptomatic hypomagnesemia. JNCI; 2005:Vol 97, 16; 1221-1224.

5. Lajer H, Daugaard G. Cisplatin and hypomagnesemia. Cancer Trat Rev; 1999: 25; 47-58.

6. Schlingmann KP, Weber S, Peters M, Niemann Nejsum L, Vitzthum H, Klingel K, et al. Hypomagnesemia and secondary hypocalcemia is caused by mutations in TRPM6, a new member of the TRPM gene family. Nat Genet 2002: $31 ; 166-170$.
Correspondencia: Dr. D. Marrupe González Oncología Médica Hospital General de Móstoles Río Júcar, s/n E-28935 Móstoles (Madrid) dmarrupe.hmtl@salud.madrid.org 